\title{
Attitudes toward policies to protect open space: A comparative study of government planning officials and the general public
}

\author{
Shorna R. Broussard ${ }^{\mathrm{a}, *}$, Camille Washington-Ottombre ${ }^{\mathrm{b}}$, Brian K. Miller ${ }^{\mathrm{c}, 1}$ \\ a Department of Natural Resources, Cornell University, Fernow Hall, Ithaca, NY 14853, USA \\ ${ }^{\mathrm{b}}$ Purdue University, 195 Marsteller Street, West Lafayette, IN 47907-2033, USA \\ ${ }^{\mathrm{c}}$ University of Illinois, 1101 West Peabody Drive, MC635, 376 National Soybean \\ Research Center, Urbana, IL 61801, USA
}

Received 29 August 2006; received in revised form 6 December 2007; accepted 7 December 2007

Available online 19 February 2008

\begin{abstract}
The goals of this research were to identify factors that influence local decisions to protect open spaces and the associated natural resources and to better understand the context in which local government officials and citizens express support for additional policies to protect these resources. In order to determine community opinions related to land use and natural resources, a mail survey was administered to a random sample of adult residents and all local planning commission officials in the 22 counties in Indiana's Upper Wabash River Basin. A comparative analysis was done to determine the relationship between attitudes of citizens and planning officials and how this can inform policy. This information can aid in determining public willingness to incorporate natural resources into land use plans as it compares to local government official's willingness to protect natural resources and open spaces. Results of this research will assist communities as they cope with balancing issues of community growth, environmental protection, and quality of life.
\end{abstract}

(C) 2008 Elsevier B.V. All rights reserved.

Keywords: Planning officials; Land use planning; Survey research; Open space protection

\section{Introduction}

The sprawl of human habitat in rural areas has been identified as America's leading land use problem, resulting in excessive conversion of farmland, open space, and natural resources into a residential landscape (Daniels and Lapping, 2005). Indeed, the conversion of private open land into a human-residential landscape constitutes a major threat to wildlife habitat (Odell et al., 2003). McGranahan argues that a link exists between high amenity values and rural population growth (McGranahan, 1999). Consequently, the presence of natural amenities has a significant explanatory influence on regional economic growth (Deller et al., 2001). Natural amenities attract in-migrants but also endanger the sustainable development of rural communities. Essentially, rural areas face a dilemma between the demand

\footnotetext{
* Corresponding author. Tel.: +1 607255 2149; fax: +1 6072550349.

E-mail addresses: Srb237@ cornell.edu (S.R. Broussard), cottombr@purdue.edu (C. Washington-Ottombre), millerbk@uiuc.edu (B.K. Miller)

${ }^{1}$ Tel.: +1 217244 9329; fax: +1 2173338046 .
}

to preserve local amenities and the demand for development in order to assure economic growth (Gottlieb, 1995).

Traditional land management, based on market mechanisms and governmental planning, has failed to assure the preservation of private open space (Daniels and Lapping, 2005). A "new challenge" faces planners and urges them to go beyond the traditional dichotomy of pro-development and pro-environment philosophies and to evolve from planning for development towards planning for both preservation and natural resource management (Bengston, 1994; Jonas and Bridge, 2003; Daniels and Lapping, 2005). Daniels et al. define "smart growth" as "the promised and continued development and economic growth coupled with environmental improvement and greater social integration" (Daniels and Lapping, 2005). Smart growth policies have been part of the agenda of an ever-widening range of organizations as a possible solution to the dilemma described above (Ye et al., 2005). But even if some authors try to provide a clear definition of smart growth, Ye et al. (2005) argue, based on a detailed study of the agenda of many organizations using the term smart growth, that multiple meanings of the term are sometimes employed (Ye et al., 2005). However, the need 
for "more and better local planning", and for the maturation and development of the concept of "smart growth," or growth control, is necessary (Norton, 2005; Ye et al., 2005).

Incorporating social values into land use planning is one way to assure more balanced planning. Social values have been used in land use planning to better understand highly valued amenities in communities (Tyrväinen et al., 2007), to determine residents' attitudes toward a conservation approach to development (Austin, 2004), and to identify attitudes toward protection of open-space (Illinois Department of Natural Resources, 2003). If plans are to succeed, planners have to involve a wide array of stakeholders and incorporate their views into the planning process (Burby, 2003; Bengston et al., 2004).

If properly implemented, the factors positively influencing support for "smart growth" and sustainable land use planning could help to improve political practices (Ye et al., 2005). There are many factors that contribute to our understanding of support for growth controls (Miller, 2003). The population growth perspective implies that land use controls are more likely to be adopted in areas with high population growth or at least in areas where population growth is perceived as a major local issue (Rudel, 1984; Pratt and Rogers, 1986; Connerly and Frank, 1986; Anglin, 1990; Baldassare and Wilson, 1996).

The community affluence perspective implies that communities with higher socioeconomic status are more likely to impose land use controls to protect property values. There is not widespread agreement that affluence fully explains one's attitudes, however. Van Leere and Dunlap (1980) reviewed 21 empirical studies that assess the degree to which social and economic factors explain differences in environmental concern and concluded that income provided only a limited explanatory significance of support for environmental concern. However, through an analysis of New Jersey's 1998 Ballot measure, Solecki et al. found that support for open space protection was particularly high in the "wealth belt" area of north central New Jersey (Solecki et al., 2004). In spite of the controversial aspect of this theory, it still seems valuable to take the community affluence perspective into account (Rudel, 1984; Pratt and Rogers, 1986; Solecki et al., 2004).

The growth machine theory "explains the relationship between land-based elites such as developers and businesses that benefit from the exchange value of the land and homeowners and residents who benefit from the use value of the land" (Miller, 2003). The exchange value refers to the value realized when a commodity is sold or rented, whereas the use value refers to the direct utility that one receives from its consumption. The growth machine theory predicts differences in growth control support depending on whether an individual is related to land through exchange values, in which case growth limits would be opposed, or through use values, in which case growth controls would be favored (Pfeffer and Lapping, 1994; Green et al., 1996; Flora, 2000). Analyzing data from a survey conducted in Wisconsin, Green et al. (1996) concluded that seasonal residents who had a use value of the land favored land use controls more so than did permanent residents who supported economic development. The growth machine theory is complemented by the local dependency thesis which implies that people who are related to the land by both exchange and use values are less likely to support growth controls (Cox and Mair, 1988).

Quality of life theory implies that residents dissatisfied with their present quality of life or who predict a negative perceived change in their current quality of life would be more likely to support growth control policies (Johnston, 1980; Gottdiener and Neiman, 1981; Connerly and Frank, 1986; Anglin, 1990; Bollens, 1990; Baldassare and Wilson, 1996). From a theoretical point of view, the concept of "quality of life" is very useful in relation to land use planning. Quality of life can be defined as "a product of the interplay among social, health, economic, and environmental conditions which affect human and social development" (Bukenya et al., 2003). Indeed, quality of life is highly related to natural amenities (Reed and Brown, 2000), but is also explained by the level of education, gender and by the "hedonic treadmill" theory that relates happiness to per capita GNP (Kahn and Juster, 2002). Above all, research regarding quality of life has shown a clear relationship between the "society's institutional landscape" (Bloom et al., 2001), the "resilience of a community" (Reed and Brown, 2000) and the quality of life of the residents. This definition of quality of life dovetails particularly well with the definition of "smart growth" given above, and makes natural amenities one of its main concerns.

Management of quality of life has been recommended as a prime criterion of local growth management policies (Miller, 2003). Current quality of life and the perceived potential change in quality of life were significant predictors of the level of support for growth controls (Miller, 2003). Planning officials need assistance in estimating a level of growth for their county that will maintain or improve quality of life to the level desired (Miller, 2003). Therefore, focusing the interest of planners towards quality of life issues might help in building sustainable land use plans (Dissart and Deller, 2000; Reed and Brown, 2000; Bloom et al., 2001; Bukenya et al., 2003; Marshall, 2004). Indeed, it has been shown that people's migration to rural areas is related to quality of life outcomes (Beesley and Bowles, 1991; Van Praag et al., 2003; Boelter and Mays, 2004). From a more general point of view, quality of life can be seen as both a way to evaluate policies and also as the main objective of policies (Bukenya et al., 2003; Dissart and Deller, 2000; Kahn and Juster, 2002).

Planners are important intermediaries between the built environment and the people that live in it (Devlin, 1991; Hubbard, 1997). However, much of previous research on attitudes toward growth controls has focused solely on residents or planners, but not both. Some studies have been comparative in nature (Greenberg et al., 1987; Calavita and Caves, 1994; Ryan, 2006). One of the first studies to compare attitudes of planners with another group was a study conducted by Greenberg et al. (1987). They interviewed public health officers and planners in $18 \mathrm{New}$ Jersey townships and investigated their views toward the risks, impacts, and land use implications associated with toxic and hazardous waste sites. Greenberg et al. (1987) found that planners had a "speak no evil" (p. 341) stance and were reluctant to discuss the negative consequences of hazardous waste sites. Specifically, planners in this study did not believe there was a need to curtail development or incorporate the potential impacts associated with hazardous waste sites into planning decisions. 
Calavita and Caves (1994) surveyed planners and the general population in San Diego County with the goal of determining views on quality of life and issues related to growth. The authors defined growth as the "expansion of developed space due to population growth and economic development.'(p. 484). In terms of quality of life, there were no significant differences between planners and the general population. Slightly more than half of the planning and general population respondents agreed that the quality of life in San Diego County was experiencing a decreasing trend. However, planners and the general population in this study differed significantly on their perceptions of growth trends in San Diego County; $75 \%$ of the general population agreed that the county was growing too fast while less than half of planners felt that the County was growing too fast. Also, planners were significantly more reluctant to favor slowing growth when compared to residents. When asked if the costs or problems associated with growth outweigh the benefits, statistically significant differences were found between the attitudes held by the general public and planners; $48 \%$ of the general public agreed that the costs of development outweigh the benefits, while only $32 \%$ of planners agreed with this statement. While the socioeconomic status of planners, in terms of education and income, was higher than that of the general public, Calavita and Caves (1994) did not find socioeconomic status to have a significant relationship with attitudes. These researchers concluded that planners' views in favor of development were independent of their socioeconomic status.

Ryan (2006) surveyed residents, planners, and developers in the Western Massachusetts town of Sunderland. Preserving rural character held importance to residents, planners, and developers, but was most important to local residents. Additionally, local residents believe nature is an important contributing factor to rural character, more so than did planners or developers. The community characteristics of proximity to nature and cultural elements held significantly more importance to local residents compared to planners and developers.

While residents and planners both favor preserving rural character and have similar views related to quality of life, there were significant divergences of opinion on the level and type of growth that was acceptable and the role of open space. These comparative studies have shown that nature is a significantly more central characteristic to residents than planners. Also, planners have a much higher tolerance for growth and development when compared to residents. Planners hold much more confidence that the benefits of development outweigh the costs whereas residents tend toward a precautionary principle and believe that the costs are greater. Planners are more reluctant to divulge the negative consequences of development and are more reluctant to slow growth. Since planners are making decisions on behalf of their community and the residents that live there, it is important for more residents to be involved in planning and for planners to acknowledge and incorporate the varying views held by the residents. These divergences are significant and it is for these reasons that we felt it imperative to examine the views of residents and planners and build on previous studies in this area. No investigation has ever been done on the willingness of residents to support growth control policies in Indiana where specific issues regarding conversion of farmland, open space, and natural resources into residential landscape are at stake. Building on previous research, this study aims to provide useful information for planning issues in Midwestern rural communities.

In order to better understand land use planning in a Midwestern region of the United States, many issues concerning the relationship between the willingness to protect natural resources and the support for growth control policies have to be addressed. In this study, we respond to the following three research questions:

(1) How do residents and plan commission members differ, if at all, in their attitudes toward growth and development in their county?

(2) Under what conditions, if any, do residents and plan commission members feel growth and development should be limited in their county?

(3) How do perceptions of population growth, size of community, affluence, quality of life, and growth machine theory influence, if at all, residents and planners attitudes toward growth controls?

\section{Project study area: the Upper Wabash River Basin}

The Upper Wabash River Watershed is located in Northern Indiana and is highly fragmented by row-crop agriculture and urbanization. Indiana is in the Midwestern region of the United States, an area of the country known for social and political conservatism (Indiana Agriculture and Natural Resources Land Use Working Group, 1997). Land use policy in the state reflects both an agrarian history and a strongly held belief in individual property rights (Indiana Agriculture and Natural Resources Land Use Working Group, 1997). Planning, zoning, and other forms of government oversight regarding land use are anathema to conservatives who deny the government's right to intervene in property-use decisions. While $71 \%$ of Indiana's population resides in urban areas (U.S. Census, 2001), the study region has a slightly smaller proportion of urban residents (66\%). Indiana's rural areas are characterized by small family farms, however, the Indiana Farmland Protection program stated in a recent report that Indiana was " 4 th highest in the nation in the percent of 1997 developed land that was prime farmland in 1992 and 7th in the U.S. in the average annual loss of prime farmland to development from 1992-1997. With almost 70\% of the state being considered prime or important farmlands, the majority of the increase was obtained at the expense and the loss of prime or important farmlands" (USDA, 2003).

\section{Survey methodology}

A mail survey with five waves of mailings was implemented using the Tailored Design Method (Dillman, 2000). U.S. Survey Sampling International of Fairfield, CT, provided the resident sample. The survey was mailed to a stratified random sample of residents $(n=2000)$ and all planning commissioners $(n=218)$ in Indiana's Upper Wabash River Basin in north-central Indiana. The Upper Wabash River Basin contains 22 counties, covers 5 
million acres, has a population of 841,090 people (U.S. Census, 2000 ) and represents $21 \%$ of the land area of Indiana. This region was selected because it is an area with high rurality coupled with increasing residential development pressure. The sample of residents was weighted by population in each county. The response rate was $47 \%(n=729)$ for the residents and $58 \%(n=126)$ for the planning commissioners.

Planning officials responded to questions on the survey from the perspective of a planning official in the county in which they work and adult residents (18 years or older only) were asked to answer the questions from the perspective of the county in which they reside. Survey respondents were given the following definition of growth and development: "Indiana's counties are growing at different rates. Growth is occurring in both urban and rural areas in several forms including industrial, residential, population, economic development, agricultural industries, etc. Together these forms of growth collectively change the economy and land uses of your county. This set of questions asks your opinions about growth and development in your county."

Scale development for rating of community characteristics, factors affecting residency, abundance of natural resources, and perception of open space was achieved by using principle components analysis extraction method on the correlation matrix (individual questions are listed in Appendix A). Factors with eigenvalues over 1, a standard criterion for determining factor selection, were extracted. Varimax rotation with Kaiser normalization, a form of orthogonal rotation which minimizes factor correlation, generated the rotated component matrix. From this, factor scores were saved as regression variables (Grice, 2001), upon which subsequent analyses were conducted. We use Cronbach's $\alpha$ to assess the reliability of the attitudinal measures used in this study (see Appendix A for full listing). Cronbach's $\alpha$ ranges from 0 to 1.0. The natural resources and recreation scale contains 5 items (availability of outdoor activities, availability of recreational opportunities, opportunities to view wildlife, opportunity to enjoy natural surroundings, rural character) and has a reliability of 0.82 for residents and 0.73 for planners. The financial interests scale contains 3 items (easy to sell, investment and part of financial security, in an area with high resale values) and exhibited a reliability of 0.84 for residents and 0.86 for planning officials. The aesthetic interests scale consists of 4 items (desired aesthetic characteristics, area with little or no traffic, enjoy natural beauty/wildlife, refuge from everyday pressure) and exhibited a reliability of 0.57 and 0.75 for residents and planners, respectively. The abundance of public open space scale contains 4 items (abundance of forest lands, wetlands, wildlife, and public open space) and has a reliability of 0.78 for the residents sample and 0.70 for planning officials. The abundance of private open space has 3 items (abundance of agricultural lands, private open space, and rural areas) and exhibited a reliability of 0.72 for residents and 0.75 for planners. The benefits of open space scale contains 5 items (improve fishing conditions, reduce waste water treatment costs, reduce flooding, reduce drinking water treatment costs, improve the supply of ground water) and has a reliability of 0.78 for the resident sample and 0.74 for the planning officials. The negative per- ceptions of open space benefits scale has 4 items (harbor pests and mosquitoes, can be unsightly, rate less tax revenue, increase animal and insect populations that damage crops) and has reliabilities of 0.70 and 0.73 for residents and planners, respectively. The open space as unutilized space scale contains 3 items (unutilized space, should be developed, discourage businesses from locating in the community) and has reliabilities of 0.54 for residents and 0.56 for plan commissioners. Lastly the open space is revenue generating scale had 2 items (provide revenue, attraction for tourism) and exhibited reliabilities of 0.48 and 0.70 for residents and planning officials. Two of the open space perceptions scales (open space as unutilized space and open space provides revenue) are slightly below the conventional accepted minimum $\alpha$ of 0.60 (DeVillis, 1991), but were retained for analysis because generally a lower $\alpha$ is acceptable for exploratory scale development.

Multiple linear regression was used to examine the influence of the following independent variables: perceptions of open space, factors affecting residency, quality of life, growth perceptions, and demographics on the dependent variable of adequacy of current policies to protect open space. The dependent variable is a 5-point policy adequacy scale where $1=$ no (adequate) policies, ordinances, or other protections, $2=$ only a few (adequate) policies, ordinances, and other protections, $3=$ no opinion, $4=$ some (adequate) policies, ordinances, or other protections, and $5=$ (many) adequate policies, ordinances, and other protections. While the dependent variable in this study is ordinal in that the distance between each categorical level of variable is not necessarily equal, it has been firmly established in the psychometric research literature that ordinal data of five or more categories can be treated as continuous and analyzed using statistical analyses such as regression, analysis of variance, and correlation (Borgatta and Bohrnstedt, 1980). Treating ordinal survey data as continuous for such statistical procedures has been established as both reliable and robust (Davison and Sharma, 1988, 1990; Gregoire and Driver, 1987; Rasmussen, 1989). Therefore, the 5-point ordinal dependent variable was considered to continuous in the regression analyses in this research. Lastly, mean comparisons and Chi-square analyses were used to analyze differences between residents and planners for education, political ideology, type of community and residence, property ownership, perception of growth rates, tenure, perceived abundance of agricultural lands, perceived abundance of wildlife habitat, gender, adequacy of environmental protection, and limits to protection. All analyses were conducted using SPSS Version 12.0 .

\section{Results}

Frequencies, mean comparisons, and Chi-square analyses provide a first view of the attitudinal and demographic differences between the two survey groups: all local planning officials and the general public residing in the counties for which the planning commissioners work. The results begin with a description of the planner and general public respondents. 
Table 1

Descriptive and inferential statistics for residents and plan commissioners

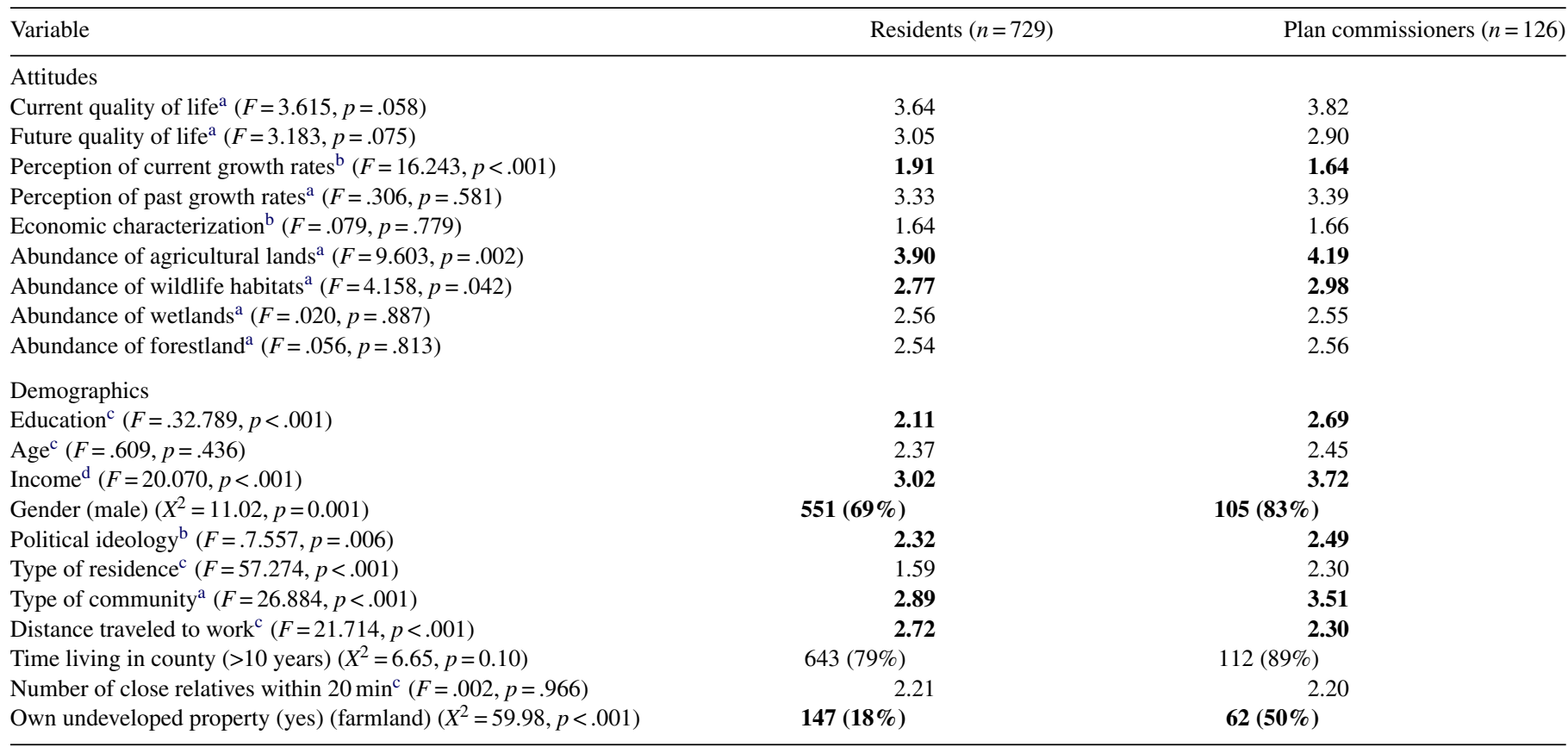

Statistically significant differences are in bold.

a 5-Point scale.

b 3-Point scale.

c 4-Point scale.

d 6-Point scale.

\subsection{Sample description}

Table 1 contains descriptive statistics and comparisons from individual questions on the survey. Overall, local planning officials are more educated, more politically conservative, and have higher annual household incomes than the general public in the study area (Table 1). Planners are also more likely to live in rural areas and own undeveloped property than are adult residents and there are a significantly greater proportion of males in the planning official community compared to adults responding to the survey. Lastly, residents travel greater distances to work than do planning officials. No differences between residents and planners were found for the demographic variables of age, type of residence, and the number of close relatives living nearby. Compared to Indiana residents, both the resident and plan commissioner sample contained a lower percentage of females; $49 \%$ of Indiana's population is female compared to $31 \%$ of resident respondents and $17 \%$ of plan commissioner respondents (U.S. Census Bureau, 2002). For educational achievement, both the resident and plan commissioner samples were more educated than Indiana residents overall, with the starkest contrast between overall statistics for Indiana residents and plan commissioners (U.S. Census Bureau, 2002). Fewer survey respondents had less than a high school education compared to statewide figures; $18 \%$ of adults in Indiana do not have a high school diploma or GED compared to $6 \%$ of resident survey respondents and $0 \%$ of plan commissioners. Also, $12 \%$ of Indiana adults have a B.S. degree compared to $17 \%$ of resident survey respondents and $33 \%$ of plan commissioners (U.S. Census Bureau, 2002).
Local planning officials perceive agricultural lands and wildlife habitat in their county as more abundant than the general public does. But residents and planners share similar views on the abundance of forest lands and wetlands. Residents perceive present growth rates as "just about right" whereas local officials think the current rate of growth is "too little". The two survey groups have concordant perceptions of past growth rates (stayed about the same or slight increase) and the economic characterization of the county (declining and struggling economically) (Table 1). Residents and planning officials share the same use values toward the land and are deeply attached to their county. More precisely, $32 \%$ of the general public and $34 \%$ of the local officials have more than 8 close relatives living within $20 \mathrm{~min}$ from their home; and $79 \%$ of the general public and $89 \%$ of the local officials have lived in their county for more than 10 years.

Local officials perceive a slightly higher current quality of life than general public. On a 5-point scale, $26 \%$ of local officials fall on the upper spectrum of the scale indicating they have a "very desirable" current quality of life, in contrast with only $12 \%$ of the general public. Both planners and residents have a low expectation of their future quality of life; on a 5-point scale only $5 \%$ of residents affirm that their quality of life is "getting much better" and only $2 \%$ of the local officials share this view.

Research Question 1: How do residents and planners differ, if at all, in their attitudes toward growth and development in their county? 
Table 2

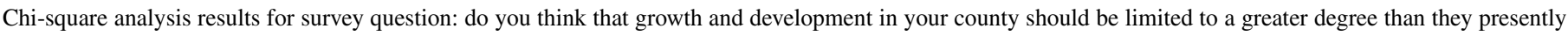
are?

\begin{tabular}{|c|c|c|}
\hline & Residents \% (n) & Plan commissioners $\%(n)$ \\
\hline $\begin{array}{l}\text { Response category 1: no, growth and development in my county should not be limited any } \\
\text { more than it currently is }\end{array}$ & $23.9 \%(188)$ & $9.2 \%(19)$ \\
\hline $\begin{array}{l}\text { Response category 2: no more limitations are needed, we just need to follow and enforce the } \\
\text { county's comprehensive plan, policies, and corresponding ordinances }\end{array}$ & $21.0 \%(165)$ & $33.3 \%(42)$ \\
\hline $\begin{array}{l}\text { Response category 3: slight limitations are needed in the county's comprehensive plan, } \\
\text { policies, and corresponding ordinances }\end{array}$ & $24.0 \%(189)$ & $17.5 \%(22)$ \\
\hline $\begin{array}{l}\text { Response category 4: moderate limitations are needed in the county's comprehensive plan, } \\
\text { policies, and corresponding ordinances }\end{array}$ & $22.5 \%(177)$ & $29.4 \%(37)$ \\
\hline $\begin{array}{l}\text { Response category 5: major limitations are needed in the county's comprehensive plan, } \\
\text { policies, and corresponding ordinances }\end{array}$ & $8.5 \%(67)$ & $4.8 \%(6)$ \\
\hline Total & $100 \%(786)$ & $100 \%(126)$ \\
\hline Chi-square statistics & \multicolumn{2}{|c|}{$X^{2}=17.149$, d.f. $=4, p=.002$} \\
\hline
\end{tabular}

Respondents selected among the 5 response categories noted in the table.

We used Chi-square analysis to test the null hypothesis that there is no difference between residents and planners on the limitations to growth attitude (Table 2). Residents and planners selected a response along a continuum from "no limitations needed" to "major limitations needed" in growth and development. The within sample and across sample differences are explained below.

Residents (24\%) were more than twice as likely than planners $(9 \%)$ to report that growth and development should not be limited. Planners (33\%) were more likely than residents (21\%) to believe that the best course of action would be to follow and enforce current plans and policies. Similar proportions of residents $(24 \%)$ and planners $(18 \%)$ believe that either slight or moderate limitations were needed. While only a small proportion of residents (9\%) and planners (5\%) believed that major limitations were necessary, residents were nearly twice as likely to hold that belief.

In addition to the comparisons of planners and residents above, it is worth noting the results within each sample as well. Within the sample of planners, they were divided in their views regarding options related to controlling growth and development. A subset of planners $(33.3 \%)$ felt strongly that enforcing current plans and ordinances is all that is necessary while another subset $(29.4 \%)$ held strong attitudes that moderate limitations to existing comprehensive land use plans are needed. Within the sample of residents, there were three salient attitudes regarding options related to controlling growth and development. Many residents felt that growth and development should not be limited (23.9\%), while others believed that either slight (24.0\%) or moderate $(22.5 \%)$ changes were needed to comprehensive land use plans and ordinances in order to control growth and development.

Research Question 2: What reasons, if any, do planners and residents feel are appropriate for limiting growth and development in their county?

An additional set of questions was asked to residents and planners that believed slight, moderate, or major limitations are needed to land use plans, policies, and ordinances. Respondents that did not feel changes were needed to land use plans, policies, and ordinances were not directed to respond to these questions. The follow-up questions were meant to capture the reasoning behind decisions favoring limitations to current growth in their county. Frequencies of responses for residents and planners are listed in Table 3. We used Chi-square analysis to test the null hypothesis that there is no difference between residents and planners in their responses to these 6 questions. The null hypothesis is rejected for "to avoid an increase in government spending," "to prevent environment from deteriorating," and "to maintain the present character of my county." Significantly more residents favored growth controls to prevent environmental deterioration and to avoid an increase in costs associated with development while planners held significantly stronger attitudes than resi-

Table 3

Chi-square analysis results for survey question: if you indicated above that growth and development in your county should be limited to a greater degree than it presently is, please circle all of the reasons why you would like to limit growth

\begin{tabular}{|c|c|c|}
\hline & \multicolumn{2}{|c|}{ Respondents indicating YES \% $(n)$} \\
\hline & Residents $(n=433)$ & Plan commission members $(n=65)$ \\
\hline To avoid an increase in government spending and taxes $\left(X^{2}=8.816\right.$, d.f. $\left.=1, p=.003\right)$ & $23.0 \%(162)$ & $11.2 \%(14)$ \\
\hline To prevent the environment from deteriorating $\left(X^{2}=8.523\right.$, d.f. $\left.=1, p=.004\right)$ & $44.4 \%(313)$ & $30.4 \%(38)$ \\
\hline To prevent an increase in traffic congestion and overcrowding $\left(X^{2}=2.086\right.$, d.f. $\left.=1, p=.149\right)$ & $35.5 \%(250)$ & $28.8 \%(36)$ \\
\hline To maintain present real estate values $\left(X^{2}=.216\right.$, d.f. $\left.=1, p=.642\right)$ & $16.9 \%(119)$ & $15.2 \%(19)$ \\
\hline To maintain the current quality of life $\left(X^{2}=.157\right.$, d.f. $\left.=1, p=.692\right)$ & $39.7 \%(280)$ & $41.6 \%(52)$ \\
\hline To maintain present character of my county $\left(X^{2}=6.802\right.$, d.f. $\left.=1, p=.009\right)$ & $26.2 \%(185)$ & $37.6 \%(47)$ \\
\hline
\end{tabular}

Respondents were presented with each choice above and could select all that applied. 
Table 4

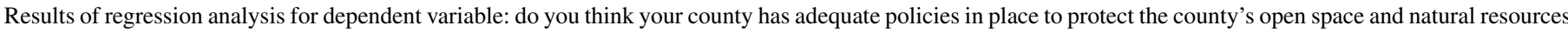
(water, wildlife, timber, etc.)?

\begin{tabular}{|c|c|c|}
\hline & \multicolumn{2}{|c|}{ Standardized coefficients $(\beta)$} \\
\hline & Residents & Plan commissioners \\
\hline \multicolumn{3}{|l|}{ Perceptions of open space } \\
\hline Attitude that private open space is abundant & $.086^{*}$ & -.001 \\
\hline Attitude that public open space is abundant & $.146^{* * *}$ & .152 \\
\hline Positive perceptions of open space & -.031 & .041 \\
\hline Negative perceptions of open space & .067 & $.218^{* *}$ \\
\hline Attitude that open space is unutilized space & $.086^{* *}$ & -.080 \\
\hline Attitude that open space is revenue generating & .014 & .013 \\
\hline Attitude that open space provides aesthetics and recreation & .060 & .003 \\
\hline \multicolumn{3}{|l|}{ Factors affecting residency } \\
\hline Financial interests and motivations & .037 & $.254^{* *}$ \\
\hline Aesthetic interests and motivations & -.040 & .097 \\
\hline \multicolumn{3}{|l|}{ Quality of life } \\
\hline Attitude that current quality of life is desirable & .050 & -.071 \\
\hline Attitude that quality of life is getting better & $.095^{* *}$ & .136 \\
\hline \multicolumn{3}{|l|}{ Growth perceptions } \\
\hline Attitude that county has experienced an increase in growth & .039 & .105 \\
\hline Attitude about strictness of control county exercises over growth & $-.278^{* * *}$ & $-.315^{* * *}$ \\
\hline \multicolumn{3}{|l|}{ Demographics } \\
\hline Age & .013 & .045 \\
\hline Education & $-.091^{* *}$ & -.167 \\
\hline Income & -.040 & .045 \\
\hline Liberal $($ ref. $=$ conservative $)$ & -.052 & -.074 \\
\hline Moderate (ref. = conservative) & -.013 & -.087 \\
\hline \multicolumn{3}{|l|}{ Model statistics } \\
\hline$R^{2}$ & .231 & .376 \\
\hline Adjusted $R^{2}$ & .202 & .250 \\
\hline$F$ & 7.972 & 2.984 \\
\hline$p$-Value & $>.001$ & $>.001$ \\
\hline d.f. & 18 & 18 \\
\hline
\end{tabular}

5 -Point scale from $1=$ no adequate policies to $5=$ many adequate policies .

* $p<.06$.

** $p<.05$.

*** $p<.005$.

dents in terms of favoring growth controls in order to maintain the present character of the community. The null hypothesis is accepted for "to prevent an increase in traffic congestion and overcrowding," "to maintain real estate values," and "to maintain current quality of life." Residents and planners did not differ in their attitudes toward implementing growth controls to maintain real estate values or to prevent traffic congestion. Also, while not statistically significant, quality of life was a concern for both residents and planners.

Research Question 3: How do perceptions of population growth, size of community, affluence, quality of life, and growth machine theory influence, if at all, residents and planners attitudes toward growth controls?

The dependent variable in the model is adequacy of current policies to protect open space and natural resources in their county. For residents, the independent variables perceptions of open space, factors affecting residency, quality of life, growth perceptions, and demographics explained $20 \%$ of the variance on adequacy of current policies to protect open space and the model was significant (adjusted $R^{2}=.202, p<.001$ ) (Table 4). Strong attitudes about the abundance of public and private natural resources and viewing natural resources as occupying space which could otherwise be utilized all correspond to a perception that current polices are adequate. There is an inverse relationship between the level of control the county exercises over growth and adequacy of current policies. This is also true for the demographic variable of education. That is, the belief that current policies to protect open space are adequate decreases with education and with low levels of government control over current growth. Stated another way, the most educated residents believe that current policies are inadequate as do those that believe current growth controls are weak.

For planners, independent variables of perceptions of open space, factors affecting residency, quality of life, growth perceptions, and demographics explained $25 \%$ of the variance on adequacy of current policies to protect open space and the model was significant (adjusted $R^{2}=.250, p<.001$ ). Attitudes toward the adequacy of current open space protection policies was influ- 
enced most by financial interests and motivations, beliefs about the negative impacts of open space, and perception about the level of control county currently exercises over growth. Planners that decided to locate in the community for financial reasons (investment, financial security, high resale values, easy market to sell in) were more likely to think that current policies were adequate. Also planners were more likely to believe that current policies are adequate if they had strong beliefs regarding the negative impacts of open space such as thinking these areas harbor pests and are unsightly. A belief that current control over growth is too strict corresponds to a belief that current polices are adequate; this result was the same for both residents and planners.

\section{Discussion}

This research confirms that planners and residents have different views about land use planning and its consequences. Thus, their decisions are arrived at through a unique, and often differing, set of set of drivers. For planners, those decisions impact an entire community. There is a real need for planners to broaden their understanding of citizen values so that those values are reflected in land-use decisions.

For local planning officials, drivers like personal values such as important factors in choosing a place of residence, growth perceptions, and the association of natural resources with negative impacts influenced their willingness to protect the environment. However, residents were greatly influenced by perceptions of values associated with open space and quality of life. Residents support for growth controls were sensitive to the amounts of both public and private open space and, whereas planners were not. There were also divergences between planners and residents in growth perceptions. As in Calavita and Caves (1994), residents in this study perceived the growth rate to be higher than did planners and planners were also more reluctant to slow that growth.

Consistent with previous research, planners in this study favored development (Calavita and Caves, 1994). The importance of the exchange value of the land likely led planners to associate growth with further development and future economic opportunities, consistent with the growth machine theory (Rudel, 1984; Pratt and Rogers, 1986; Connerly and Frank, 1986; Anglin, 1990; Baldassare and Wilson, 1996). Planners were more than three times more likely to own undeveloped investment property than residents and also financial interests were a significant influence on their attitudes toward policies to protect open space.

This research supports the quality of life hypothesis, which posits that a lower quality of life is associated with greater willingness to control growth (Johnston, 1980; Gottdiener and Neiman, 1981; Connerly and Frank, 1986; Anglin, 1990; Bollens, 1990; Baldassare and Wilson, 1996). As resident's quality of life decreases so did their belief that current policies to protect natural resources are adequate. While Calavita and Caves (1994) found no differences between planners and residents in terms of quality of life perceptions, quality of life was a factor driving residents to a greater extent than planners in this study. Additionally, Ryan (2006) found that nature and proximity to nature were central to the general public's views of what was most important to preserve in their community. The results of this study similarly show that natural resources associated with open space were of great importance to residents.

In this study, key differences were uncovered when examining thresholds for limiting growth and development. For residents, controlling government spending and preventing environmental degradation were the most important reasons for placing limits on growth and development in their county. For planners, their chief concern was preserving the character of their county. Both were supportive of limiting growth and development for purposes of maintaining real estate values and quality of life and for avoiding the often resultant traffic congestion. However, the most telling of these results is that residents were more supportive of environmental protection concerns in the arena of growth and development than were planners. This is consistent with previous research that shows that nature is less central to planner's decisions and they are less supportive of considering the environmental consequences and other "costs" of development (Calavita and Caves, 1994; Ryan, 2006). The result is also consistent with the population growth perspective which implies that in areas where high growth rates are perceived, growth control policies are more likely to be adopted (Baldassare and Wilson, 1996). Planner's attitudes about the adequacy of policies were also influenced by their financial interests. To the extent that financial considerations were key to planners moving to their county, they were also likely to feel that no more needs to be done in terms of policies to protect natural resources.

In terms of demographic characteristics, education also appeared to play a role in potential support for policies to protect natural resources as those residents that were the most highly educated were aware that current policies were not in place to adequately protect natural resources. Income was not a significant influence predictor of growth control support for residents nor planners; however financial interests and motivations did influence growth control support for planners.

The goals of this research were to identify factors that influence local decisions to protect the open spaces and associated natural resources and better understand the context in which local government officials and citizens express support for additional policies to protect these resources. Sharp differences between local officials and residents concerning the structure of their willingness to place additional protection on the environment and to support growth control policies have been brought to light by this research. Building on the commonalities and being aware of these differences, local planning officials can "make informed policy decisions" that incorporate natural resource protections into planning for growth and development (Diener and Suh, 1997). Exploring reasons for differences between planners and residents regarding the need to protect open space would be a first step toward creating growth controls for conservation. 


\section{Appendix A. Appendix to Table 4}

Individual survey items and reliability statistics for factor scales.
Resident sample $\mathrm{Plan}$

$(n=729)$

Cronbach's $\alpha$

sample $(n=126)$

Cronbach's $\alpha$

Item 4: I wanted my home to be a refuge or escape from everyday pressure

Factor scale: abundance of public

open space (how would you characterize the abundance of the following types of land that support natural resources in your county? 1 = scarce, $2=$ moderately scarce, $3=$ adequate, $4=$ moderately abundant, 5 = abundant) Item 1: forestlands in my county Item 2: wetlands in my county Item 3: wildlife in my county Item 4: public open space in my county

Factor scale: abundance of private open space (how would you characterize the abundance of the following types of land that support natural resources in your county? 1 = scarce, 2 = moderately scarce, 3 = adequate, $4=$ moderately abundant, 5 = abundant)

Item 1: agricultural lands in my county

Item 2: private open space in my county

Item 3: rural areas in my county

Item 4: can help reduce drinking water treatment costs to the community

Item 5: can improve the supply of groundwater in the community

Factor scale: negative perceptions of open space (please complete the following sentence with the phrases below. "In my opinion, forests, grasslands, wetlands, and other nonagricultural lands are, ..." 1 = strongly disagree, 2 = disagree, $3=$ neutral, 4 = agree, 5 = strongly agree)

Item 1: harbor pests and mosquitoes Item 2: can be unsightly

Item 3: generate less tax revenue than residential development

Item 4: increase animal and insect populations that damage crops

Factor scale: open space as unutilized space (please complete the following sentence with the phrases below. "In my opinion, forests, grasslands, wetlands, and other nonagricultural lands are, ..., 1 = strongly disagree, 2 = disagree, $3=$ neutral, 4 = agree, 5 = strongly agree)

Item 1: I wanted my community to provide the aesthetic characteristics I desire

Item 2: I wanted my home to be in a area with little or no traffic

Item 3: I wanted my home to be located in a way that I can enjoy natural beauty around my home or yard 
Resident sample Plan

$(n=729) \quad$ commissioner

Cronbach's $\alpha \quad$ sample $(n=126)$

Cronbach's $\alpha$

\begin{tabular}{l}
\hline Item 1: unutilized space \\
Item 2: should be developed \\
Item 3: discourage businesses from \\
locating in the community \\
Factor scale: open space is revenue 0.48 \\
generating (please complete the \\
following sentence with the \\
phrases below. "In my opinion, \\
forests, grasslands, wetlands, \\
and other nonagricultural lands \\
are, ... 1 = strongly disagree, \\
$\mathbf{2}=$ disagree, $\mathbf{3}=$ neutral, \\
$\mathbf{4}=$ agree, $\mathbf{5}=$ strongly agree) \\
Item 1 : can provide opportunities for \\
revenue on which local businesses \\
depend \\
Item 2 : can be attraction to tourists
\end{tabular}

\section{References}

Anglin, R., 1990. Citizen preferences for local growth. Urban Aff. Q. 25, 684-696.

Austin, M.E., 2004. Resident perspectives of the open space conservation subdivision in Hamburg Township, Michigan. Landscape Urban Plan. 69 (2-3), 245-253.

Baldassare, M., Wilson, G., 1996. Changing sources of suburban support for local growth controls. Urban Studies 33 (3), 459-471.

Beesley, K., Bowles, R., 1991. Change in the countryside: the turnaround, the community, and the quality of life. Rural Sociol. 11 (4), 37-46.

Bengston, D., 1994. Changing forest values and ecosystem management. Soc. Nat. Resour. 7, 515-533.

Bengston, D.N., Fletcher, J.O., Nelson, K.C., 2004. Public policies for managing urban growth and protecting open space: policy instruments and lessons learned in the United States. Landscape Urban Plan. 69, 271-286.

Bloom, D.E., Craig, P.H., Malaney, P.N., 2001. The Quality of Life in Rural Asia, Oxford and Manila. Oxford University Press and Asian Development Bank.

Boelter, A., Mays, K., 2004. Public Opinion in Wyoming on Conserving Agricultural Lands and Open Space. Wyoming Open Spaces, University of Wyoming.

Bollens, S., 1990. Constituencies for limitation and regionalism: approaches to growth management. Urban Aff. Q. 26, 46-67.

Borgatta, E.F., Bohrnstedt, G.W., 1980. Level of measurement: once over again. Sociol. Methods Res. 9, 147-160.

Bukenya, James O., Gebremedhin, Tesfa G., Schaeffer, Peter V., 2003. Analysis of quality of life and rural development: evidence from West Virginia data. Growth Change 34 (2), 202-218.

Burby, B., 2003. Making plans that matter, citizen involvement and government action. APA 69 (1), 33-49.

Calavita, N., Caves, R., 1994. Planners' attitudes toward growth: a comparative case study. J. Am. Plan. Assoc. 60 (4), 483-500.

Connerly, C., Frank, J., 1986. Predicting support for local growth controls. Soc. Sci. Q. 67, 572-585.

Cox, K., Mair, A., 1988. Locality and community in the politics of local economic development. Ann. Assoc. Am. Geogr. 78, 307-325.

Daniels, T., Lapping, M., 2005. Land preservation: an essential ingredient in smart growth. J. Plan. Lit. 19 (3), 316-329.

Davison, M.L., Sharma, A.R., 1988. Parametric statistics and levels of measurement. Psychol. Bull. 104, 137-144.
Davison, M.L., Sharma, A.R., 1990. Parametric statistics and levels of measurement: factorial designs and multiple regressions. Psychol. Bull. 107, 394-400.

Deller, S., Tsung-Hsiu, T., Marcouiller, D., English, D., 2001. The role of amenities and quality of life in rural economic growth. Am. J. Agric. Econ. 83 (2), 352-365.

DeVillis, R.F., 1991. Scale Development: Theory and Applications (Sage University Paper Series on Applied Social Research Methods), 26 ed. Sage Publications Inc., Newbury Park, CA.

Devlin, K., 1991. An examination of architectural interpretation: architects versus non-architects. J. Archit. Plan. Res. 7 (3), 235-244.

Diener, E., Suh, E., 1997. Measuring quality of life: economic, social, and subjective indicators. Soc. Indic. Res. 40, 189-216.

Dillman, D.A., 2000. Mail and Internet Surveys: The Tailored Design Method, second ed. John Wiley \& Sons, Inc., New York.

Dissart, J.-C., Deller, S., 2000. CPL bibliography 360, quality of life in planning literature. J. Plan. Lit. 15 (1), 135-161.

Flora, C., 2000. Extension and place: reducing transaction costs for better communities. Rural Dev. News 24, 1-3.

Gottdiener, M., Neiman, M., 1981. Characteristics of support for local growth control. Urban Aff. Q. 17, 55-73.

Gottlieb, P., 1995. The "golden egg" as a natural resource: towards a normative theory of growth management. Soc. Nat. Resour. 8 (1), 49-56.

Green, G., Marcouiller, S., Deller, S., Erkkila, S., Sumathi, N., 1996. Local dependency, land use attitudes, and economic development: comparison between seasonal and permanent resident. Rural Sociol. 61, 427-445.

Greenberg, M., Leibowitz, J., Popper, F., 1987. Hat's off to local public health officers. J. Environ. Health 49 (6), 340-341.

Gregoire, T.G., Driver, B.L., 1987. Analysis of ordinal data to detect population differences. Psychol. Bull. 101, 159-165.

Grice, J.W., 2001. Computing and evaluating factor scores. Psychol. Methods $6,430-450$.

Hubbard, P., 1997. Diverging attitudes of planners and the public: an examination of architectural interpretation. J. Arch. Plan. Res. 14 (4), 317-328.

Indiana Agriculture and Natural Resources Land Use Working Group, 1997. Indiana Land Use on the Edge: Report of the Indiana Agriculture and Natural Resources Land Use Working Group. Office of the Commissioner of Agriculture, Indianapolis, IN, 46pp.

Illinois Department of Natural Resources, 2003. Positive attitudes toward open space: the unmet demand for open space in Illinois, May 2003, 11pp.

Johnston, R., 1980. The politics of local growth control. Policy Studies J. 9, 424-439.

Jonas, A., Bridge, G., 2003. Governing nature: the re-regulation of resources land-use planning, nature conservation. Soc. Sci. Q. 84 (4), 958-963.

Kahn, R.L., Juster, F.T., 2002. Well-being: concepts and measures. J. Soc. Issues 58 (4), 627-644.

Marshall, E., 2004. Open-space amenities, interacting agents, and equilibrium landscape structure. Land Econ. 80 (2), 272-293.

Miller, B.K., 2003. Factors influencing the protection of open space and natural resources in county land use plans. Thesis submitted of the faculty of Purdue University, May 2003.

McGranahan, D., 1999. Natural amenities drive rural population change. Agricultural Economic Report No. 781.U.S. Department of Agriculture, Economic Research Service, Washington, DC.

Norton, R., 2005. More and better local planning. J. Am. Plan. Assoc. 71 (1), 55-71.

Odell, E., Theobald, D., Knight, R., 2003. Incorporating ecology into land use planning, the songbird's case for clustered development. APA J. 69 (1), $72-82$.

Pfeffer, M., Lapping, M., 1994. Farmland preservation, development rights and the theory of the growth machine: the view of the planners. J. Rural Studies 10, 223-248.

Pratt, S.R., Rogers, D.L., 1986. Land use controls. Rural Sociol. 51 (3), 354-362.

Rasmussen, J.L., 1989. Analysis of Likert-data: a reinterpretation of Gregoire and Driver. Psychol. Bull. 105, 167-170.

Reed, P., Brown, G., 2000. Public land management and quality of life in neighboring communities, the Chugach National forest planning experience. For. Sci. 49 (4), 479-497. 
Rudel, T., 1984. The human ecology of rural land use planning. Rural Sociol. $49,491-504$.

Ryan, R., 2006. Comparing attitudes of local residents, planners, and developers about preserving rural character in New England. Landscape Urban Plan. 75, $5-22$.

Solecki, W., Mason, R., Martin, S., 2004. The geography of support for open space initiatives: a case study of New Jersey's 1998 ballot measure. Soc. Sci. Q. 85 (3), 624-639.

Tyrväinen, L., Makinen, K., Schipperijn, J., 2007. Tools for mapping social values of urban woodlands and other green areas. Landscape Urban Plan. 79 (1), 5-19.

U.S. Census Bureau, 2002. U.S. Summary: 2000 (Census 2000 Profile). U.S. Department of Commerce, Economics and Statistics Administration. Avail- able online: http://www.census.gov/population/www/cen2000/briefs.html, $6 \mathrm{pp}$.

United States Department of Agriculture, Natural Resources Conservation Service, 2003. Indiana Farmland Protection Program: FY 2003 plan. USDANRCS, Indianapolis, IN, 11 February 2003. 17pp.

Van Leere, M., Dunlap, R., 1980. The social bases of environmental concern: a review of hypotheses, explanations and empirical evidence. Public Opin. Q. 44 (2), 181-197.

Van Praag, B., Frijters, P., Ferrer-i-Carbonell, A., 2003. The anatomy of subjective well-being. J. Econ. Behav. Organ. 51, 29-49.

Ye, L., Mandpe, S., Meyer, P., 2005. What is "smart growth?" really? J. Plan. Lit. 19 (3), 301-315. 